\title{
Characterization of Production under feed-in tariffs in Portugal Mainland
}

\author{
M. Margalho ${ }^{1}$ and P. Lourenço ${ }^{1}$ \\ ${ }^{1}$ EDP Serviço Universal, SA \\ Direção Compra de Energia \\ Av. Urbano Duarte, 100 - 3030-215 Coimbra (Portugal) \\ Phone number: +351 239002 000, e-mail: mariana.margalho@edp.pt, pedro.lourenco@edp.pt
}

\begin{abstract}
EDP Serviço Universal (EDP SU), in its core business, must ensure the purchase of energy from producers under special regime and distributed production, with feed-in tariffs, and sell it through spot and future markets. Furthermore, the company must ensure the purchase of energy in those markets for the supply of its customers. The process of buying and selling electricity is quite complex from the legislative and regulatory point of view.

In Portugal, over the last two and a half decades, high focus on the promotion of renewable energies has been set, particularly through power plants with feed-in tariffs, which has increased the use of internal energy resources and has stimulated the reduction of the country's energy dependence. During this process, the development of related legislation and the dynamism of the sector, with the introduction of incentives which prompted the investment and promoted the maturation of new technologies, has been essential.

The present work characterizes the producers to whom EDP SU purchases energy, with emphasis on technologies, number of installations, installed power, geographic location and acquired energy, showing the evolution over last years.
\end{abstract}

\section{Key words}

Purchasing and Selling of Electricity, Production Under Feed-in Tariffs, Distributed Production, EDP Serviço Universal, Last Resort Supplier

\section{Introduction}

The production and efficient use of electricity are, nowadays, more and more a concern in sustainable development. There are major concerns about climate change on the planet: increasing demand for energy, high prices for non-renewable energy sources, limiting greenhouse gas emissions, among others. In this context, it is imposed the necessity to change behaviour by seeking greater energy efficiency, introducing renewable energies and rationalizing environmental resources.

Thus, in the recent years, European energy policy has been encouraging the state members to be energetic efficient and independent from fossil resources.
At the national level, legislation has been created to increase the use of endogenous and renewable energy resources, reduce greenhouse gas emissions, and expand distributed production, allowing production at small-scale and self-consumption. However, the investment required to create infrastructures in order to achieve European targets to produce energy from renewable sources are high. Hence, the legislation establishes feed-in tariffs that encourages producers under special regime and make the investments viable.

The greater use of endogenous and renewable resources to produce electricity has changed the composition of the electricity production mix in Portugal and has played a determinant role in the satisfaction of consumption, as presented in the Fig. 1.:

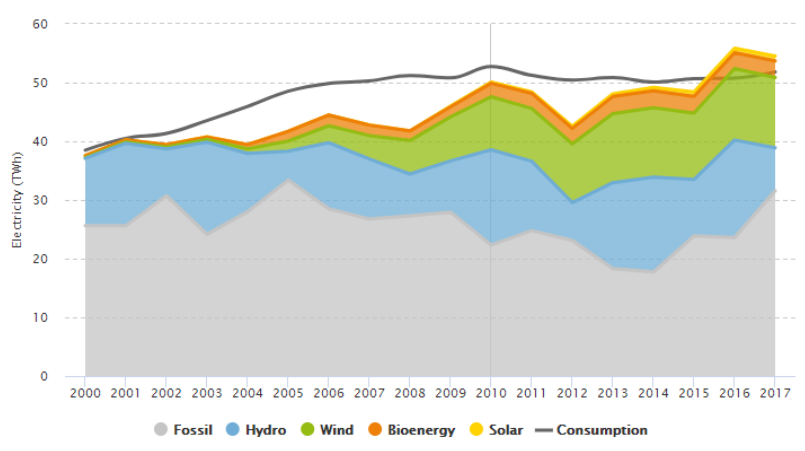

Fig. 1. Evolution of electricity production in mainland Portugal Source: APREN [1]

The results of the policies implemented in Portugal, are quite evident, being, in 2016, the second country with the highest percentage of incorporation of renewables in the electricity sector, as shown on Fig. 2. 


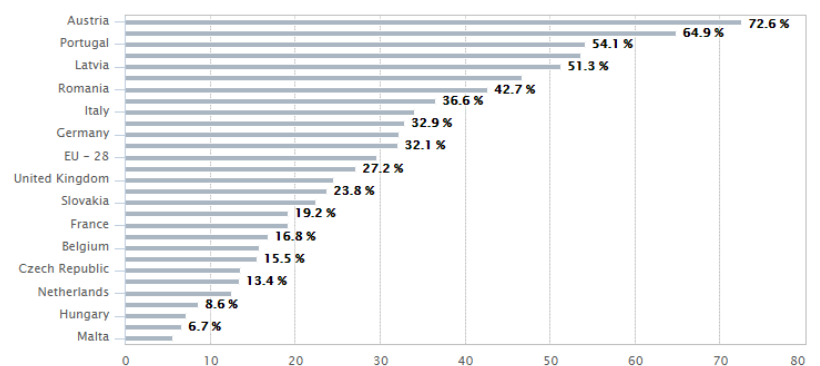

Fig. 2. Percentage of the incorporation of renewables into the electricity sector in the EU-28 in 2016.

Source: Eurostat, 2018

\section{EDP Serviço Universal}

EDP Serviço Universal (EDP SU) is a company of the EDP Energias de Portugal, S.A, which buys and sells electric energy, exercising its activity as Last Resort Supplier.

In Portugal, the Last Resort Supplier, besides being entitled with the commercial licence, in the exercise of activity, has the obligation of universal provision of the electricity supply service to consumers at a regulated tariff. Also, it performs the role of sole buyer of production under special regime under feed-in tariffs, being likewise responsible for the acquisition of the energy produced by the distributed production with contract of selling to that utility.

In order to promote greater efficiency and transparency in the purchasing and selling of electricity the last resort supplier's activity is detached into these roles:

- Purchasing and selling of electricity for consumption by its customers. As a last resort supplier, it has to purchase all required electricity to satisfy the consumption needs of its customers in organised markets (spot or future) or through bilateral contracts with producers, suppliers or other licensed entities.

- Purchasing and selling of electricity from special regime producers, under feed-in tariffs, and sale of all this energy in the Iberian market, at market prices.

\section{Characterization of production under special regime}

According to the legislation in force, it is considered production under special regime the activities licensed under special juridical regimes, adopting policies to encourage the production of electricity, namely by using renewable resources or combined heat and power technologies. In recent years in Portugal, these installations have been constantly evolving for most technologies. Regarding the mix of installation technology, this has been undergoing a change over the last years. [1] In 2000, hydro installations were predominant and representing around $46 \%$ of all installations under feed-in tariffs, non-renewable cogeneration was about 39\% and only $9 \%$ were wind farms. Nowadays, it is the photovoltaic technology that has more number of installations. Wind farms represent about $24 \%$ of total installations, non-renewable cogenerations as well as hydros represent only 10\%, as shown in Fig. 3.
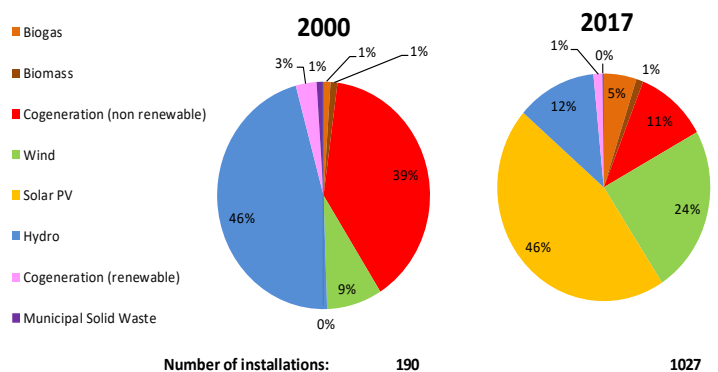

1027

Fig. 3. Characterization of the number of installations under feed-in tariffs by technology in 2000 and 2017 Source: EDP SU

Although the largest number of installations being photovoltaic, it represents only $3 \%$ of the total capacity installed, as around $75 \%$ of these installations have power installed until $5 \mathrm{kVA}$. As shown in Fig. 4, wind farms are the technology predominant, representing 69\% of the all capacity installed under special regime.
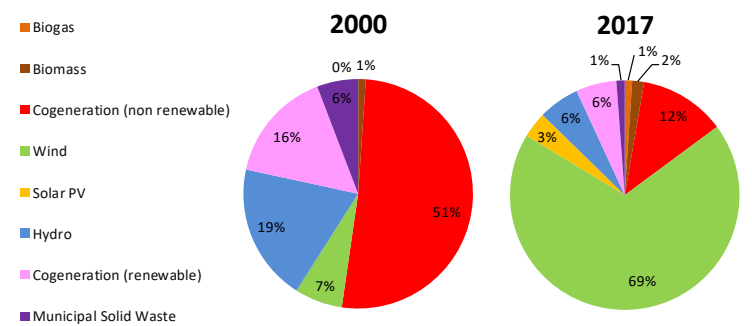

Installed capacity (MVA): $\quad 1631$

8105

Fig. 4. Characterization of installed capacity of production under feed-in tariffs by technology in 2000 and 2017

Source: EDP SU

Analysing the evolution of installed power since 2000, it is notorious the increase of wind power over the time. The continuous growth of wind power is justified in a first stage by the legislative revision, in 2001, which gave a financial incentive to new installations. At a second stage, the legislation allowed the installations of new towers in the existing wind farms and there were also open tenders for the availability of injection power, based on discounts at the feed-in tariffs. In Portugal, the power installed under feed-in tariffs, by type of technology, is presented in Fig. 5. [5]

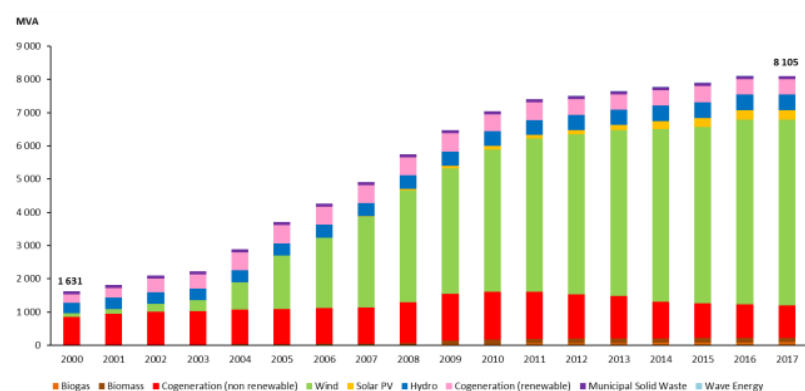

Fig. 5. Evolution of installed capacity for production under feed-in tariffs in Portugal (MVA) Source: EDP SU 
Over the last few years, the evolution of installed capacity by regions has not been reflected homogeneously in the country. As shown in Fig. 6, there has been a greater concentration of power installed in the northern interior of the country, justified by the growth of wind farms in regions more favourable to this technology.

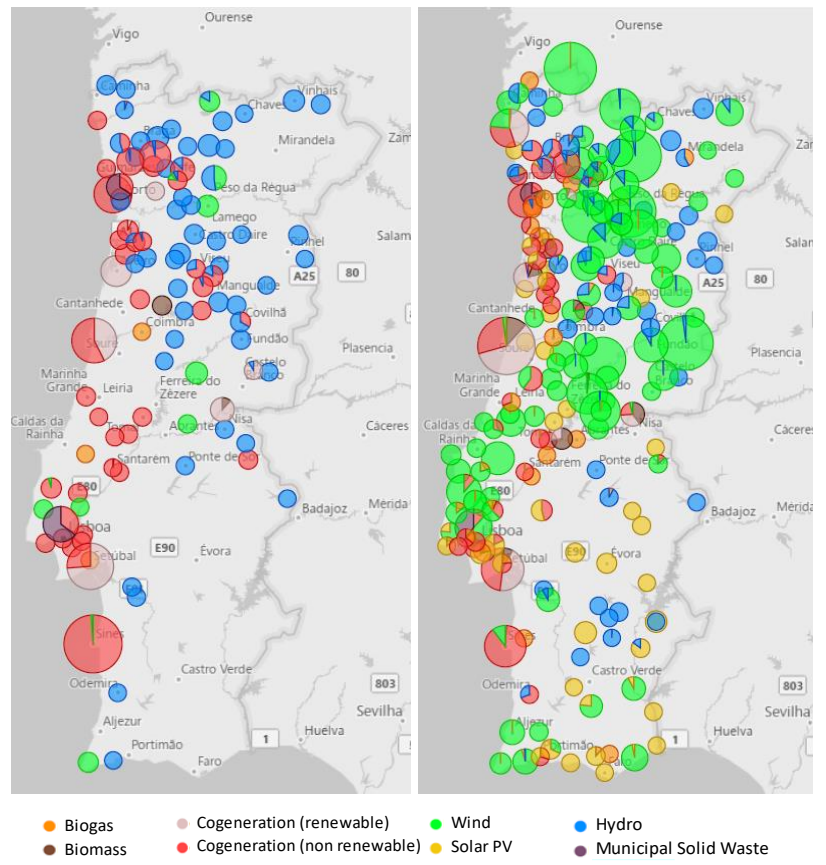

Fig. 6. Installed capacity under feed-in tariffs in 2000 and 2017 by region

Source: EDP SU

Recently there have been several periods in which the installed capacity of renewables in Portugal was sufficient to meet the total consumption needs. There were even periods when the energy produced surpassed the demand and there was exportation. In exceptional situations, the Transmission System Operator (TSO), as Global Technical Manager of the System, in order to guarantee the network safety and the production-consumption equilibrium, sent power reduction orders with the purpose of controlling the production of some installations. [3] Despite this, Portugal will continue to focus on the growth of renewables and the diversification of the technology mix. On the one hand, taking advantage of the country's solar potential and the advances of this technology, which can mean into more appealing investments, and forest potential, with new biomass installations dispersed throughout the territory. And on the other hand, through modernization of hydro and wind installations, making them more efficient.

According to current legislation, over the next 10 years, as shown in Fig. 7, more than $50 \%$ of active installations with feed-in tariffs, equivalent to $35 \%$ of installed capacity, at the end of 2017, will reach the deadlines established for the subsidized remuneration, transferring the producers to the general or market regime.
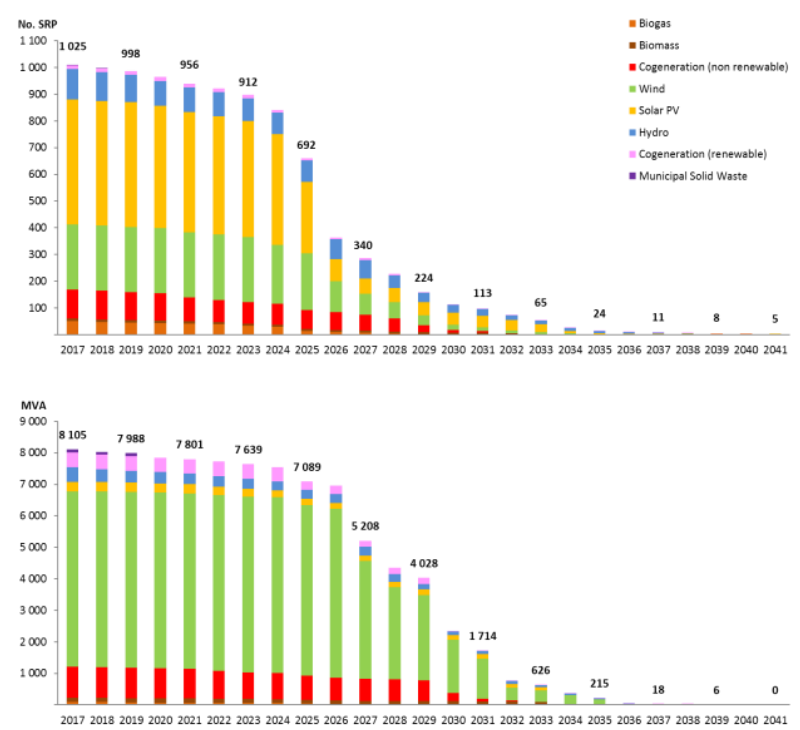

Fig. 7. Transition from producers under feed-in tariffs to market regime or to the general regime (No. of installations and installed Power) Source: EDP SU

Cogeneration installations, according to Decree-Law No. 68-A/2015, of April $30^{\text {th }}$, have the possibility, after the term legally established for the special regime, to choose to switch to the general regime, with self-consumption, with a feed-in tariff, indexed to spot market prices, or move to the market regime, where all the energy can be sold. Historically, the cogenerations that used oil as fuel, when transferred to the remuneration model establish by the Ordinance $n .^{\circ} 140 / 2012$, of May $14^{\text {th }}$, some installations were closed, due to the lack of profitability with the fall of the remuneration. On other situations, seeking better efficiency, were made changes in the installations to use gas as fuel. There were also efficient cogenerations appeal to the self-consumption regime.

The transition to the market has led hydro installations to try to set bilateral contracts with traders to sell their energy. However, due to their dimension, some have found it difficult to establish a contract and consequently sell the energy in the market for lack of an aggregating agent.

\section{Characterization of Distributed Production with contract with EDP SU}

Distributed production is the production of electricity in a decentralized way, by the consumer and close to the places of consumption, by low power units, namely solar panels, microturbines or other types of technology.

Although low voltage electricity production has been legislated since 2002, it was with the legislative changes that occurred in 2007 that started a greater evolution of installed power. According to the legislative framework in force and its characteristics they can be classified respectively as: Microproduction, Miniproduction, Small Production Unit or Production Unit with Selfconsumption. These units can still be grouped by their total sale to the grid (microprodution, miniprodution and 
small production units) and units with self-consumption (Production Unit with Self-consumption). It should be noted that, in contrast with production under feed-in tariffs, in the case of distributed production there are installations which do not set a contract with EDP Serviço Universal, such as the production units with selfconsumption with an installed capacity of more than 1 MW and installations that not inject energy on the grid.

The technological and legislative evolution of distributed production has been promoting the small scale production and self-consumption leading to a significant increase in installed power in recent years. By the end of 2017, there were 29190 units of distributed production, representing $210 \mathrm{MW}$ installed, with contracts established with EDP Serviço Universal. The evolution of the number of installations and installed capacity is presented in the Fig. 8.
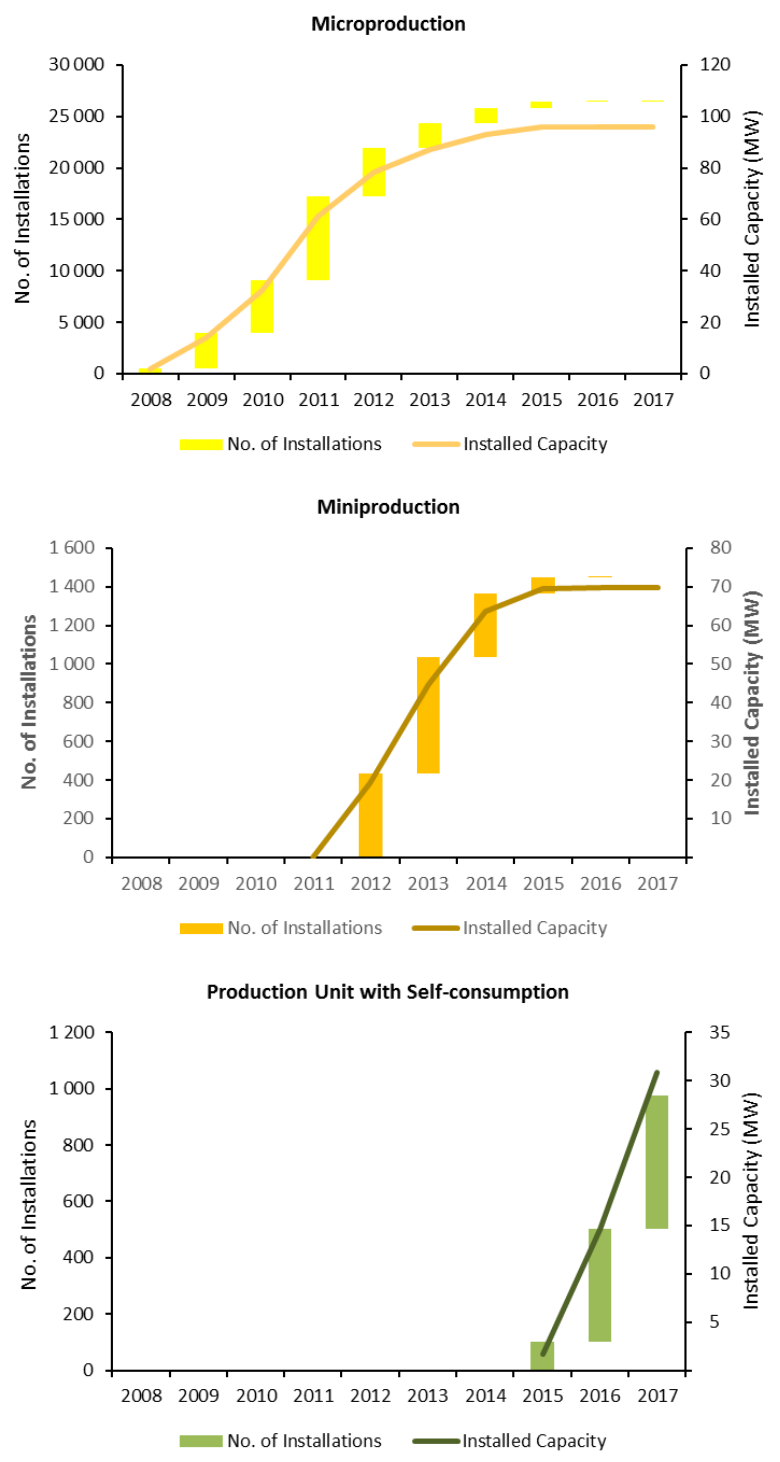

Fig. 8. Evolution of Distributed Production (No. of Installations and installed capacity)

Source: EDP SU

Of the currently available technologies, the most used in distributed production is photovoltaic, representing about $99 \%$ of the installations. One justification for this is the maturity of technology and the consequent economic profitability of these systems. [6]

\section{Purchase of Energy}

EDP Serviço Universal, as Last Resort Supplier, has the role of aggregator of production under feed-in tariffs and is legally responsible for acquiring the energy produced during legally established periods. As the installations under special regime, small producers can also benefit from a feed-in tariff, subsidized, if they meet certain conditions, or they can be submitted by a general regime, receiving a lower remuneration. In both cases, the energy is acquired by EDP Serviço Universal provided that a contract is established.

Over the last few years, there have been successive increases in production resulting from the evolution of the installed capacity of installations under feed-in tariffs and distributed production in Portugal, as presented in Fig. 9.

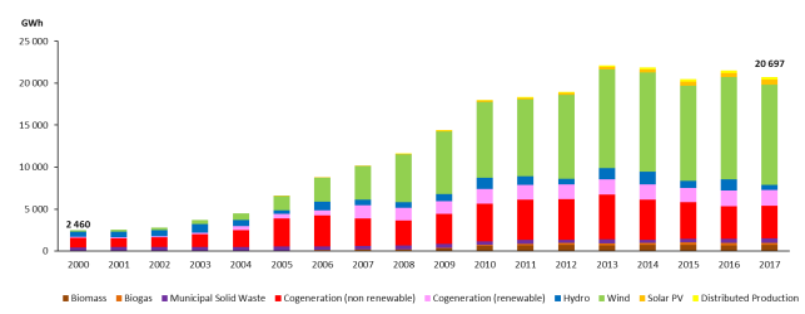

Fig. 9. Evolution of the purchase of energy by EDP SU (GWh) Source: EDP SU

During the year 2017, EDP Serviço Universal acquired $20697 \mathrm{GWh}$ from these producers, with wind power contributing to more than $50 \%$ of this total (11 942 GWh).

As shown in Fig. 10, since 2008, the installed capacity from distributed production allowed the production of 1 $550 \mathrm{GWh}$, of which $1044 \mathrm{GWh}$ were produced by microproducers, $481 \mathrm{GWh}$ produced by Miniproducers, $18 \mathrm{GWh}$ by Small Production Units and the remaining 8 GWh by Small Production with Self-consumption. 


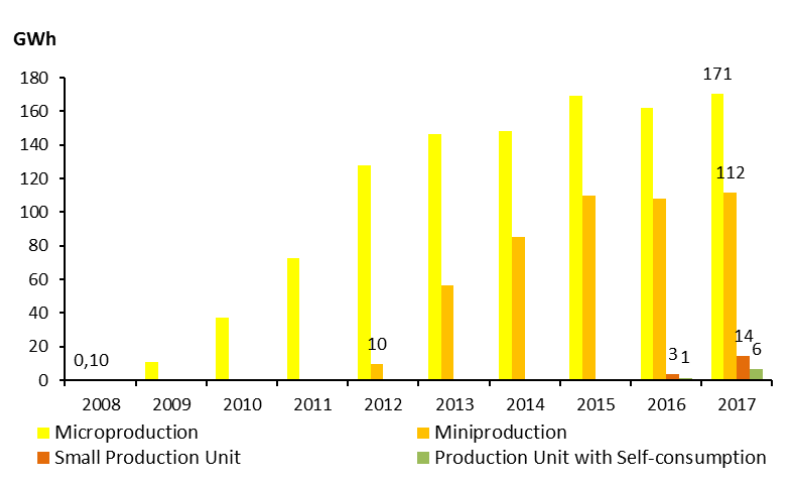

Fig. 10. Evolution of the purchase of energy to distributed production installations (GWh) Source: EDP SU

The production of renewable energy by producers under feed-in tariffs and by distributed production, represented at the end of 2017, was about $42 \%$ of the total national consumption, as can be observed by Fig. 11.

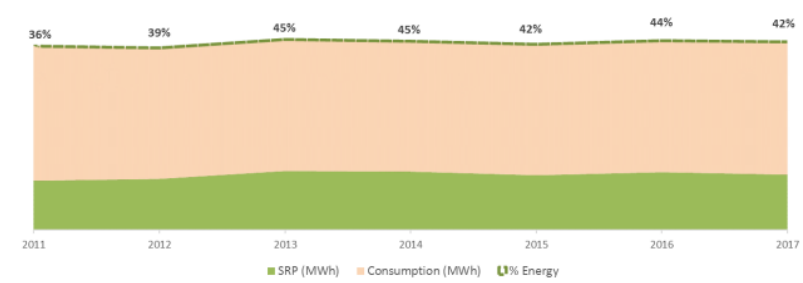

Fig. 11. Percentage of incorporation of production under feed-in tariffs in total national consumption

Source: EDP SU and REN

\section{Sale of Energy and Deviations}

EDP Serviço Universal sells the energy acquired from producers under feed-in tariffs in the Iberian Electricity Market (MIBEL). The management of MIBEL's organises energy markets in two poles. One in Spain (OMIE Iberian Energy Market Operator) that manages the daily and intraday markets and the other one is in Portugal (OMIP - Iberian Energy Market Operator) that manages derivatives exchange market.

In the electricity futures market (OMIP), energy purchase and sale contracts are transacted with a specified maturity in the future. In this market, the prices and volumes are agreed but can only be actioned at a predetermined date in the future. The energy sold by EDP Serviço Universal as futures' contracts is delivered daily during the agreed period and taken into consideration in OMIE's daily billing. As part of the participation in the derivatives exchange market, there is a clearance of results process which consists in the daily compensation of gains and losses resulting from the difference between prices agreed in the derivatives exchange market (OMIP) compared to the ones in the spot market (OMIE). The results verified since 2012 registered a positive accumulated value of 70 $\mathrm{M} €$, for the Portuguese Electrical System, showing the correct use of this instrument.

However, it is in the MIBEL's daily market that EDP Serviço Universal transacts most of the energy purchased from producers under feed-in tariffs. It is here where electricity transactions take place for next day delivery. The price is set for each hour of the day, 365 days per year. The price and volume of energy in a specific hour are determined by the point at which the supply and demand curves meet, exposing the stakeholders to high price volatility.

EDP Serviço Universal also participates on the intraday market, which allows agents to adjust their purchase and sale commitments based in one updated forecast. The Fig. 12. presents the energy volumes resulting from the sale of energy purchased from production under feed-in tariffs and distributed production, traded in the spot and future markets since 2012:

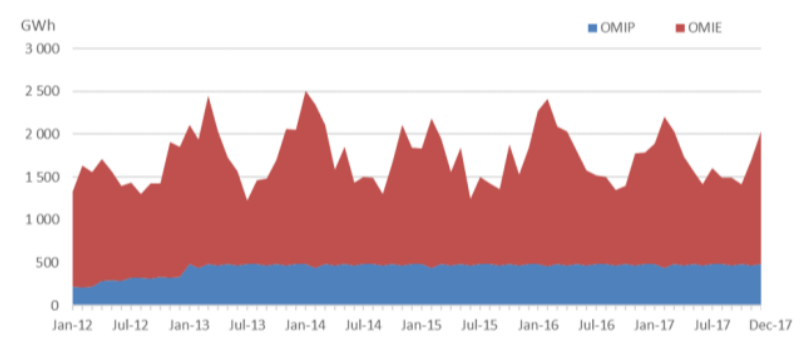

Fig. 12. Energy sold in MIBEL by EDP SU (GWh) Source: EDP SU

The auctions of energy from producers with feed-in tariffs represent a valuable contribution to the market such as for the integration of renewable energy sources into the electrical system. Moreover, it is an instrument that can be used to cover commercial risks, helping to reduce exposure to daily market price volatility as well. The sales activity makes EDP Serviço Universal responsible for forecasting the production under feed-in tariffs and distributed production in order to offer the right quantities of energy on the market and to minimize the overcosts of the deviations resulting from their sale. In recent years, it is evident that EDP Serviço Universal forecasts improved significantly, as can be observed by Fig. 13. [4]

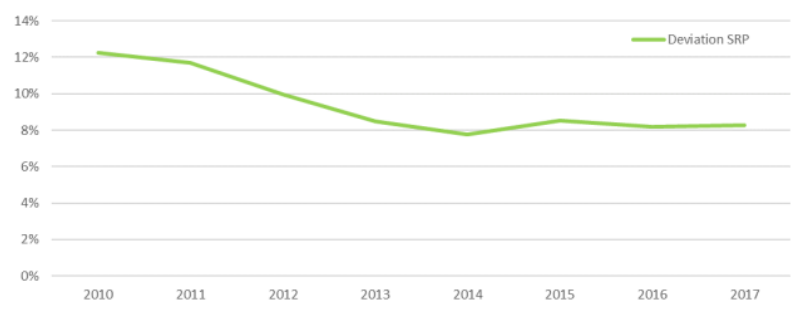

Fig. 13. Percentage of deviation of the forecast of the production under feed-in tariffs against the real value Source: EDP SU

\section{TI Systems}

The order of greatness of the production and the volume of invoicing of the production under feed-in tariffs, require a high degree of accuracy and transparency, implying the use of robust, auditable and reliable computer systems, that guarantee the quality in information reporting. Thus, two computer applications, 
the GPCE - Gestão de Produtores e de Compra de Energia and the PECUR - Previsão de Energia do CUR (Fig. 14), were developed by EDP Serviço Universal. GPCE is a shared application between Distributor System Operator (DSO) and EDP Serviço Universal. The application, in the DSO's module, includes the registration of the entire installations under feed-in tariffs licensing process and network connection data. After the connection to the grid, the producer under feed-in tariff is available to initiate invoicing with EDP Serviço Universal. In order to register and confirm the billings of producers under feed-in tariffs, all installations are individually characterized and a set of general economic parameters previously loaded in the application are used. GPCE was developed with a complex and robust programming, including all the remuneration models provided in the current legislation that allows to value the energy produced by each installation. The power is previously provided by the DSO. Equally, the application is prepared to answer to other mechanisms within the scope of legislation, such as the calculation of the interruptibility mechanism payments, as well as the calculation of the compensations under the deadline extension of Decree Law No. 35/2013, of February $28^{\text {th }}$. GPCE is also provided with a set of tools that enable the creation and submission of information reporting as well as the recording of relevant information for audit purposes.

PECUR receives, aggregates and treats data from other information systems, necessary for the preparation of the hourly forecast, made on a daily basis, for production under special regime, as well as the needs of customers in its portfolio.

These tools are indispensable for EDP Serviço Universal to interface with the transversal areas and for the elaboration of management information.

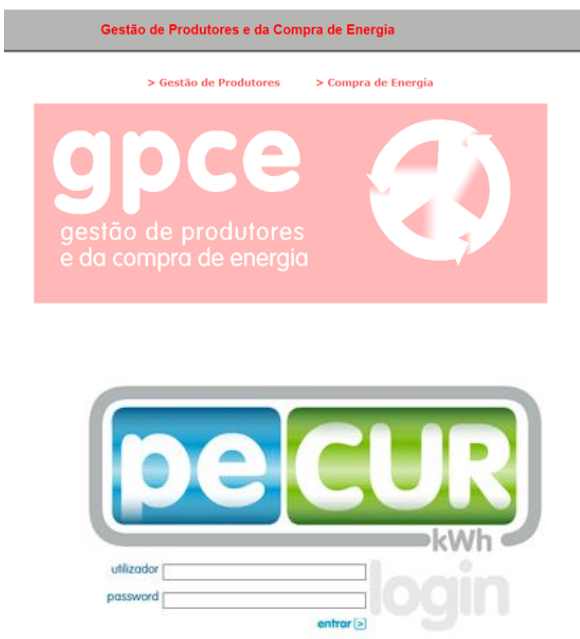

Fig. 14. Screenshot of GPCE and PECUR applications Source: EDP SU

\section{Conclusion / challenges for the future}

Portugal have made a high progress on the valorisation of efficient technologies and the installation of electric energy production solutions that use renewable and endogenous resources. It is foreseen that strong investment in this area will continue, allowing the increasingly ambitious European targets to be met. However, there are technical conditions that must be improved, such as the interconnections between the Iberian Peninsula and the rest of Europe, which will allow the exportation of the energy produced by renewables and a possible reduction of costs for consumers.

In the coming years, the dynamics of the sector will also bring some interesting challenges to EDP Serviço Universal. On the one hand, there will be a gradual transition from producers under special regime to the market or to the general regime. On the other hand, the high level of exigency and the need for continuous improvement require constant updating and automation of processes. Hence, new computer systems are being developed, replacing the current ones, in the registration and verification of the invoicing (SICUR - Sistema Integrado do CUR) and in the treatment of the information necessary to elaborate the hourly forecast of the production under special regime (EDM - Energy Data Management). The energy acquisition strategy and the continuous improvement of forecasting models, in order to reduce the level of deviations, will be other challenge of EDP Serviço Universal.

EDP Serviço Universal's constant interaction with the different stakeholders, through periodic meetings, in particular with associations from this industrial sector (APREN and COGEN), will continue to strengthen the existing business relationship with producers.

As the last resource supplier, EDP Serviço Universal, will continue to play a key role in the implementation of policies for the sector, through continuous monitoring and an effective response to all processes resulting from legislative changes.

\section{References}

[1] Associação Portuguesa de Energias Renováveis, http://www.apren.pt/pt/energias-renovaveis/, October 2018

[2] Entidade Reguladora dos Serviços Energéticos, http://www.erse.pt/pt/electricidade/Paginas/default.asp, September and October 2018

[3] António Brito, Luis Neves, "The Innovative Process in the Interruption of Wind Power in Portugal", 3rd International Conference on Power and Renewable Energy (ICPRE'18), Berlim, 2018

[4] Ana Taborda, Patricia Andrade, "EDP Serviço Universal's energy market performance", International Conference on Renewable Energies and Power Quality (ICREPQ'18), Salamanca, 2018

[5] Pedro Lourenço, Cristina Almeida, "Production under feedin tariffs in Portugal", International Conference on Renewable Energies and Power Quality (ICREPQ’17), Málaga, 2017

[6] Pedro Lourenço, Pedro Sá Furtado, "Micro-generation and Mini-generation - Sustainable production and efficient use of electrical energy in buildings", 40th IAHS World Congress on Housing, Funchal, 2014 